\title{
Matéria
}

Revista Matéria, v. 12, n. 1, pp. 164 - 172, 2007

http://www.materia.coppe.ufrj.br/sarra/artigos/artigo10863

\section{Estudo da Interação Células Vero/PLGA após a Modificação da Superfície por Plasma de Oxigênio}

\author{
Andrea R. Esposito ${ }^{1}$, Carolina Lucchesi ${ }^{1,2}$, Betina M. P. Ferreira ${ }^{1}$, Eliana A. R. Duek ${ }^{1,3}$ \\ ${ }^{1}$ Laboratório de Biomateriais - CCMB/PUCSP \\ Sorocaba, São Paulo, SP. CEP: 18030-230 \\ e-mail: deia_esposito@yahoo.com.br, biene_bmp@hotmail.com \\ ${ }^{2}$ Departamento de Histologia e Embriologia - IB/UNICAMP \\ CP: 6109. Campinas, São Paulo, SP. CEP: 13083-863 \\ e-mail: clucchesi@pucsp.br \\ ${ }^{3}$ Departamento de Engenharia de Materiais - FEM/UNICAMP \\ CP: 6122. Campinas, São Paulo, SP. CEP: 13083-970 \\ e-mail:, eliduek@pucsp.br
}

RESUMO

A aplicação de polímeros bioreabsorvíveis como suporte para cultura de células é um método alternativo para o tratamento de lesões e perdas teciduais. A modificação da superfície desses polímeros por plasma é uma técnica efetiva e econômica para torná-los mais hidrofílicos e melhorar a adesão celular. O objetivo deste trabalho foi estudar as interações entre células Vero e suportes de PLGA previamente tratados por plasma de oxigênio, com o objetivo de aumentar a hidrofilicidade da superfície desses materiais. As amostras foram caracterizadas através das análises de ângulo de contato, MEV e citoquímica. O tratamento por plasma melhorou a adesão e a proliferação celular, em relação às membranas sem tratamento.

Palavras chave: PLGA, plasma, células vero.

\section{Study of Vero cells/PLGA Interaction after Surface Modification by Oxygen Plasma}

\section{ABSTRACT}

The application of bioreabsorbable polymers as support for cells culture is an alternative method to treat lesions and loss of tissues. The surface modifications of these polymers by plasma is an effective and economical technique to make it more hydrophilic. The aim of this work was to study the interactions between Vero cells and PLGA supports previously treated by oxygen plasma, to increase the surface hydrofilicity. The samples were characterized by contact angle, MEV and citochemical analysis. The plasma treatment increased the hydrofilicity, improving the adhesion and cell proliferation, in comparison with the membranes without treatment.

Keywords: PLGA, plasma, vero cells.

\section{INTRODUÇÃO}

O poli(ácido láctico-co-ácido glicólico) (PLGA) é um poliéster bioreabsorvível que vem se tornando importante como suporte na engenharia de tecidos. Entretanto, tem baixa hidrofilicidade e não possui sítios naturais de reconhecimento para ancoragem celular [1].

As células Vero são consideradas modelo para este tipo de estudo, pois podem sofrer alterações sob a ação de diferentes fatores [2] ], incluindo as interações com o substrato [프, $\underline{4}$. Essas células possuem um padrão de crescimento caracterizado por uma morfologia alongada e crescimento em monocamadas sobre plástico ou vidro $[\underline{4}, \underline{5}]$. 
FERREIRA et al. [7] realizaram um estudo de cultura de células Vero sobre membranas de PLLA e PHBV. Os autores mostraram que existe uma baixa adesão dessas células nos polímeros estudados, porém relatam que a interação célula/polímero existe, mas é fraca [6]. Recentemente, FERREIRA et al. [8] realizaram um estudo de caracterização das membranas de PLLA e PHBV tratadas com plasma e mostraram que havia uma melhora na hidrofilicidade e consequentemente uma possível melhora na adesão celular.

A modificação da superfície por plasma é uma eficiente e econômica técnica de tratamento de superfícies para muitos materiais e está ganhando o interesse da engenharia biomédica [9]. A vantagem desse tipo de modificação é que as propriedades da superfície e a biocompatibilidade podem ser aumentadas seletivamente, enquanto os atributos do material permanecem inalterados [10].

WAN et al. [1] e CROLL et al. [11] estudaram o efeito do plasma sobre membranas de PLGA e observaram uma melhora na hidrofilicidade. A interação do plasma de ar sob baixas temperaturas em filmes poliméricos causa principalmente mudanças na polaridade da superfície [12]. Os autores também sugerem que o tratamento com plasma pode levar a uma melhora na adesão celular, pois a adesão em superfícies biológicas é uma conseqüência da adsorção de proteínas pelo substrato. Essas interações envolvem espécies

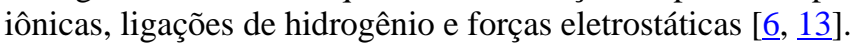

O objetivo deste trabalho foi estudar as interações entre células Vero e suportes de poli(ácido láctico-co-ácido glicólico) (PLGA) previamente tratados com plasma de oxigênio sob diferentes condições de pressão.

\section{MATERIAIS E MÉTODOS}

\subsection{Preparação das Amostras}

O polímero PLGA 50/50 foi dissolvido em cloreto de metileno 5\% (m/v) e a solução foi vertida lentamente em uma placa de Petri. Após evaporação do solvente (aproximadamente 24 horas) as membranas obtidas foram secas a vácuo. Em seguida, as amostras obtidas foram submetidas ao tratamento com plasma. Foram colocadas em uma câmara de vácuo, a uma potência de 50 ou $100 \mathrm{~W}$. Ao alcançar a pressão desejada (20 ou 80 Pa “Tab. 1") introduziu-se o oxigênio $\left(\mathrm{O}_{2}\right)$ e, então, iniciou-se a descarga do plasma. Após 600s, desligou-se o plasma, desfez-se o vácuo e as amostras foram retiradas. Para tal, utilizou-se um equipamento de plasma do tipo rádio frequência (RF) Ashing da Anatech LTD.

Tabela 1: Condições utilizadas no tratamento com plasma de oxigênio $\left(\mathrm{O}_{2}\right)$ para o PLGA

\begin{tabular}{|c|c|c|c|}
\hline Amostra & Potência (W) & Pressão (Pa) & Tempo (s) \\
\hline PLGA 0 & - & - & - \\
\hline PLGA 1 & 50 & 20 & 600 \\
\hline PLGA 2 & 100 & 80 & 600 \\
\hline
\end{tabular}

\subsection{Caracterização das Amostras}

\subsection{1 Ângulo de Contato}

O ângulo de contato das amostras foi medido em ar usando um Goniômetro NRL C.A. Goniometer Modelo 100-00 da Ramé-Hart, inc. Imaging System. A aquisição de imagens foi feita utilizando o software Rame-Hart Imaging 2001. Para a realização das medidas foi utilizada água desmineralizada deionizada e diiodometano.

\subsubsection{Microscopia Eletrônica de Varredura (MEV)}

As membranas foram colocadas em um suporte metálico e recobertas com ouro, utilizando um metalizador Sputter Coater Bal-Tec SCD 050. Em seguida, foram observadas em um microscópio eletrônico de varredura JSM 5900-LV ARP.

\subsection{Estudo in vitro - Estudo da Cultura de Células}

Foram utilizadas células Vero, provenientes do rim de um Macaco Verde africano (Cercopithecus aethiops), obtidas no Instituto Adolfo Lutz, São Paulo, Brasil. Essa linhagem é recomendada para estudos de citotoxicidade e para interações célula-substrato com biomateriais [16]. 


\subsubsection{Cultura de Células}

As células Vero foram mantidas em meio 199 (EARLE) (Nutricell Nutrientes Celulares), com 10\% de soro fetal bovino (SFB) (Nutricell Nutrientes Celulares) em estufa de $\mathrm{CO}_{2}(5 \%)$ a $37^{\circ} \mathrm{C}$. Foram realizadas trocas do meio de cultura sempre que necessário. Para avaliar a viabilidade celular, utilizou-se o método de exclusão pelo Azul de Tripan e as células viáveis foram contadas em Câmara de Neubauer.

\subsubsection{Microscopia Eletrônica de Varredura (MEV)}

Células Vero em uma concentração de aproximadamente $2 \times 10^{5}$ células $/ \mathrm{ml}$, foram lançadas sobre as membranas de PLGA tratadas e não tratadas com plasma e mantidas em meio de cultura 199 com $10 \%$ de SFB. As placas foram incubadas em estufa de $\mathrm{CO}_{2}$ a $37^{\circ} \mathrm{C}$. Após 2 e 48 horas as amostras foram mantidas durante 1 hora a temperatura ambiente em solução contendo paraformaldeído (1,25\%), glutaraldeído $(2,5 \%)$ (Sigma), ácido pícrico $(0,06 \%)$, ácido tânico $(1,0 \%)$ dissolvidos em tampão fosfato $(0,1 \mathrm{M}, \mathrm{pH} 7,4)$. Posteriormente as amostras foram tratadas com tetróxido de ósmio (1,0\%) (Sigma) e desidratadas em concentrações crescentes de etanol. As amostras foram secas em Ponto Crítico (Balzers CPD 030), recobertas com ouro, usando um metalizador (Balzers SCD 050) e observadas em microscópio eletrônico de varredura (JEOL JSM-5800 LV). Todos os experimentos foram realizados em triplicata.

\subsubsection{Análise Citoquímica}

Para o ensaio citoquímico as amostras foram submetidas as mesmas condições utilizadas no estudo da MEV. Após 2, 48 e 168 horas as amostras foram fixadas, desidratadas e coradas com azul de toluidina (AT), um corante básico que reage com grupos aniônicos e com xylidine ponceau (XP), um corante aniônico que cora grupos catiônicos. As amostras para AT foram fixadas com metanol/ácido acético 3:1 e as amostras para XP com formol 10\%. Posteriormente foram lavadas com metanol em seguida coradas e lavadas [6]. Após secas, foram montadas com entelan para observação e análise em microscópio óptico com luz polarizada (Eclipse E800 - Nikon). Todos os experimentos foram realizados em triplicata.

\section{RESULTADOS E DISCUSSÃo}

\subsection{Análise do Material}

\subsubsection{Caracterização do Ângulo de Contato}

A hidrofilicidade é um dos fatores mais importantes que afetam a citocompatibilidade dos biomateriais. A adesão e crescimento das células nas superfícies são considerados como sendo fortemente influenciados pelo balanço hidrofilicidade/hidrofobicidade, freqüentemente descritos como molhabilidade. Embora já tenha sido afirmado, anteriormente, que não há uma correlação óbvia entre hidrofilicidade e comportamento celular, alguns trabalhos demonstraram que a maior parte das células preferem se ancorar em superfícies hidrofílicas $[\underline{15}, \underline{16}, \underline{17}]$. Esses estudos mostraram ainda que as células aderem, espalham-se e crescem mais facilmente em substratos com hidrofilicidade moderada do que em substratos hidrofóbicos ou muito hidrofílicos.

O tratamento das membranas de PLGA com plasma de oxigênio causou redução no ângulo de contato com a água e aumento na energia de superfície "Tab. 2". Nota-se um aumento da hidrofilicidade na superfície das amostras provocado pelo aumento da componente polar $\left(\gamma_{\mathrm{s}}^{\mathrm{p}}\right)$ da energia da superfície.

Tabela 2: Efeito do plasma de oxigênio sobre a energia de superfície das amostras de PLGA tratadas e não tratadas sob diferentes pressões do gás, potência e tempo

\begin{tabular}{|c|c|c|c|c|c|}
\hline \multirow{2}{*}{ Amostra } & \multicolumn{2}{|c|}{ Ângulo (deg) } & \multicolumn{3}{c|}{ Energia de superfície* $\left(\mathbf{m J} / \mathbf{m}^{\mathbf{2}}\right)$} \\
\cline { 2 - 6 } & $\boldsymbol{\theta} \mathbf{H}_{\mathbf{2}} \mathbf{O}$ & $\boldsymbol{\theta} \mathbf{C H}_{\mathbf{2}} \mathbf{I}_{\mathbf{2}}$ & $\boldsymbol{\gamma}_{\mathbf{s}}{ }^{\mathbf{p}}$ & $\boldsymbol{\gamma}_{\mathbf{s}}{ }^{\mathbf{d}}$ & $\boldsymbol{\gamma}_{\mathbf{s}}$ \\
\hline PLGA 0 & 92,9 & 46,9 & 4,1 & 35,2 & 39,3 \\
\hline PLGA 1 & 62,4 & 46,8 & 17,8 & 35,0 & 52,8 \\
\hline PLGA 2 & 62,1 & 43,0 & 17,5 & 36,7 & 54,2 \\
\hline
\end{tabular}

$* \gamma_{\mathrm{s}}=$ energia de superfície, $\gamma_{\mathrm{s}}^{\mathrm{p}}=$ componente polar, $\gamma_{\mathrm{s}}^{\mathrm{d}}=$ componente dispersiva. 
Esses resultados estão de acordo com os observados por CHU et al. [10], que notaram que a hidrofilicidade está relacionada ao tipo de gás e aos parâmetros do tratamento tais como, potência, pressão e tempo utilizados.

\subsubsection{Microscopia Eletrônica de Varredura (MEV)}

A membrana de PLGA sem tratamento “Fig. 1a” apresentou uma superfície lisa com alguns orifícios. Com a aplicação dos menores parâmetros de plasma, a superfície foi levemente alterada, aumentando o número de orifícios "Fig. 1b", isso foi observado de forma clara ao se aplicar o plasma com os parâmetros mais elevados, onde a superfície sofreu uma intensa modificação, passando a apresentar uma nítida erosão "Fig. 1c".
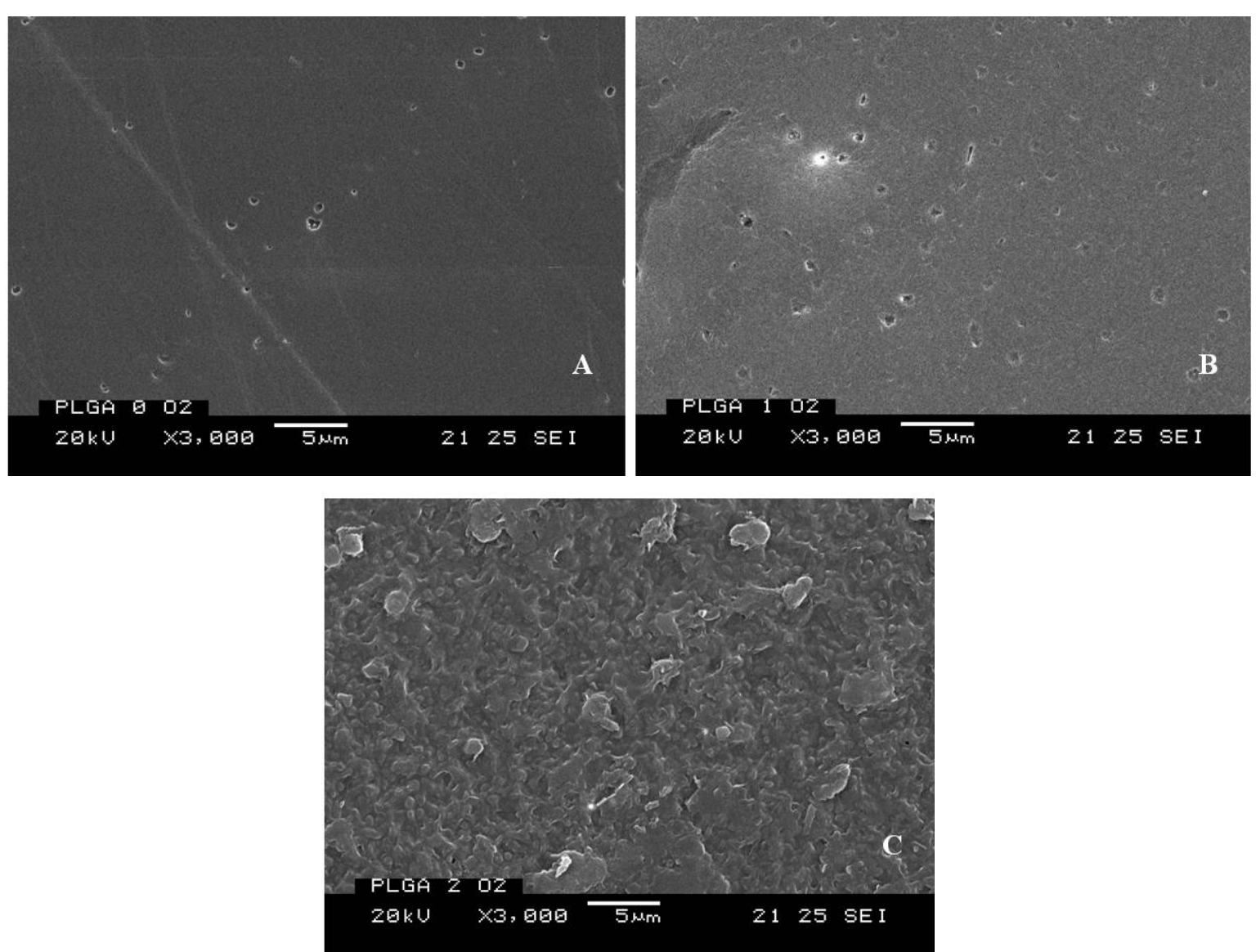

Figura 1: MEV da superfície das membranas de PLGA 50/50: (A) membrana não tratada (PLGA 0);

(B) membrana tratada com plasma, parâmetro "1" (PLGA1 O2) e

(C) membrana tratada com plasma, parâmetro "2” (PLGA2 O2).

Segundo YANG et al. [13], o aumento da rugosidade é uma das razões para o aumento da hidrofilicidade das amostras tratadas por plasma. Em resumo, podem-se modificar completamente as propriedades físicas e químicas da superfície do copolímero PLGA, utilizando-se o tratamento com plasma de $\mathrm{O}_{2}$. Além disso, não somente as modificações químicas das superfícies, mas também as mudanças morfológicas podem contribuir, independentemente, para as modificações na hidrofilicidade do PLGA.

\subsection{Estudo in vitro}

\subsubsection{Microscopia Eletrônica de Varredura (MEV)}

Os resultados obtidos através da análise por MEV mostraram que os fibroblastos iniciaram o processo de adesão e polarização celular sobre as membranas de PLGA, independente de terem sido ou tratadas (Figs. 2 e 3). 
As imagens obtidas mostraram diferenças significativas quanto à quantidade de células aderidas e ao tempo de adesão celular entre as membranas tratadas por plasma de $\mathrm{O}_{2}$, (Figs. 2B-C e Figs. 3B-C”) e as membranas que não receberam tratamento (Figs. 2A e 3A). Verifica-se que as membranas com a superfície modificada pelo plasma sob pressão de $20 \mathrm{~Pa}$ apresentaram um número evidentemente maior de células aderidas, observando-se morfologia semelhante à das células fibroblásticas [18], quando comparadas ao PLGA sem tratamento, onde não se verificou a presença de projeções citoplasmáticas e/ou vesículas.

Segundo PINHO et al. [19]], uma vez estabelecida à adesão sobre o substrato, às células passam a responder a este, alterando a sua morfologia, crescimento, proliferação, padrão de diferenciação e comportamento.

A análise das células Vero realizada após 2h de cultivo, permitiu observar padrões diversos de adesão celular para os diferentes substratos. Sobre as membranas de PLGA 0, observaram-se poucas células crescendo sobre o substrato, dispondo-se isoladamente, mostrando morfologia arredondada ou ligeiramente fusiforme, com escassa presença de material particulado sobre as superfícies celulares (Fig. 2A).

Sobre as membranas de PLGA 1 (plasma 20Pa) observaram-se células em maior número e a sua morfologia variou significativamente entre alongada e estrelada. Além disso, havia presença de filopódios e lamelipódios e uma grande quantidade de material particulado disposto sobre as superfícies celulares, apresentando um aspecto semelhante a microvilosidades (Fig. 2B). A presença de material particulado nas superfícies celulares evidencia que as células mantiveram sua capacidade biossintética. A adesão de células ao substrato não somente estimula a proliferação, mas também sua atividade biossintética [4].

As células estabelecidas sobre o PLGA 2 (plasma 80Pa) mostraram-se alongadas e aderidas ao substrato, com morfologia mais achatada e, quando observadas sob aumento maior, verificam-se células ligadas umas às outras através de alguns prolongamentos citoplasmáticos "Fig. 2c”, além de estruturas que também se assemelham a microvilosidades e/ou vesículas, porém em menor quantidade quando comparadas as membranas de PLGA 1.

Segundo REZENDE et al. [20] e KWEON et al. [21], o PLGA possui características hidrofóbicas, o que poderia justificar a baixa aderência das células às membranas de PLGA sem tratamento. Além disso, segundo YAMAGUCHI et al. [22], as células exibem boa adesão celular em materiais com ângulo de contato menor que $60^{\circ}$. WAN et al. [16] afirmam que na superfície modificada pelo plasma, aumenta-se a quantidade de grupos polares, resultando em um aumento da razão hidrofilicidade/hidrofobicidade. Os resultados obtidos das análises de ângulo de contato com a água, os quais diminuíram em aproximadamente 33\% do valor inicial $(92,9)$ com o tratamento, estão de acordo com resultados encontrados na literatura [11].

Como citado anteriormente, é conhecido que diferenças na morfologia da superfície podem influenciar o comportamento da célula [13, 23]. Segundo BERRY et al. [24], as células fibroblásticas são sensíveis às alterações na morfologia da superfície, influenciando a motilidade e possivelmente a proliferação celular.

Nas imagens observadas após 48 horas de cultivo, notou-se uma maior densidade de células, comparada à das membranas cultivadas após 2 horas. Esses dados estão de acordo com a literatura, onde observou-se que apesar da baixa adesão, as membranas de PLGA, permitiram a proliferação celular e sua capacidade de síntese [6] . Não se verificou diferenças morfológicas entre as membranas tratadas e não tratadas por plasma após 48 horas de cultivo. Observou-se uma quantidade de células aderidas semelhante entre as amostras, dispostas em monocamada com prolongamentos citoplasmáticos, filopódios e lamelipódios, e presença de material particulado sobre as superfícies celulares. Observaram-se ainda células muito próximas, sugerindo uma íntima ligação entre elas, dificultando a visualização da delimitação do contorno das células e seus respectivos limites celulares.
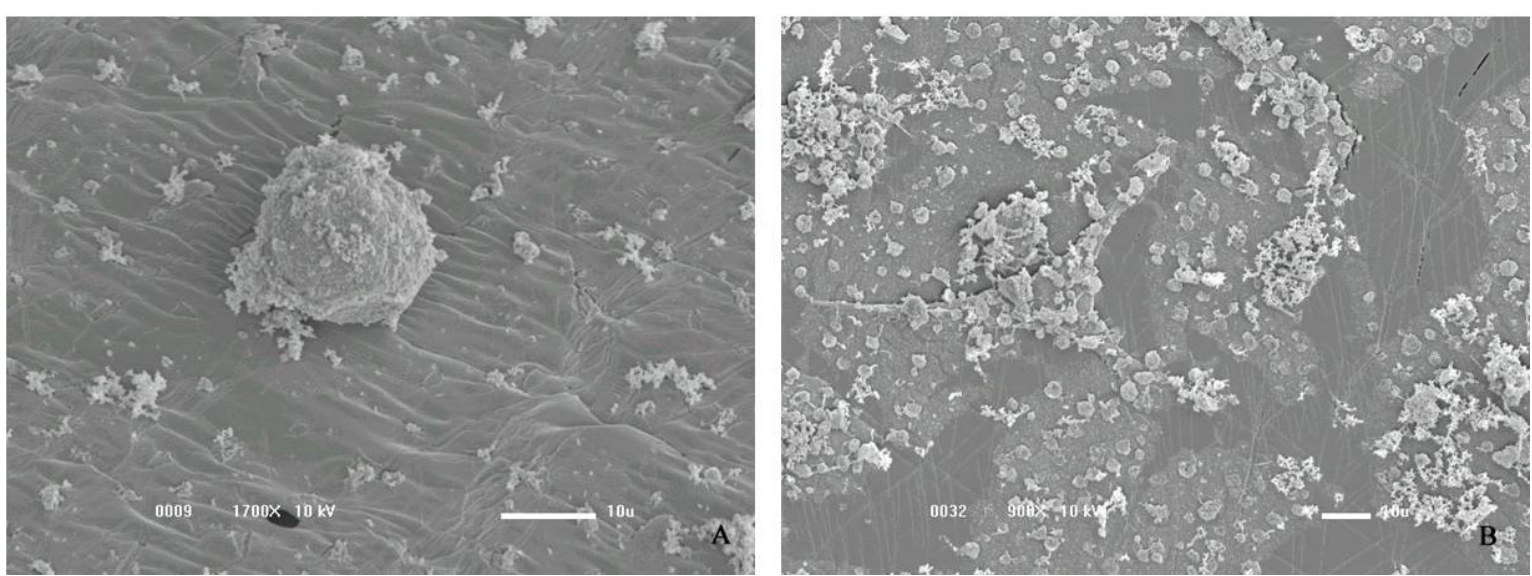


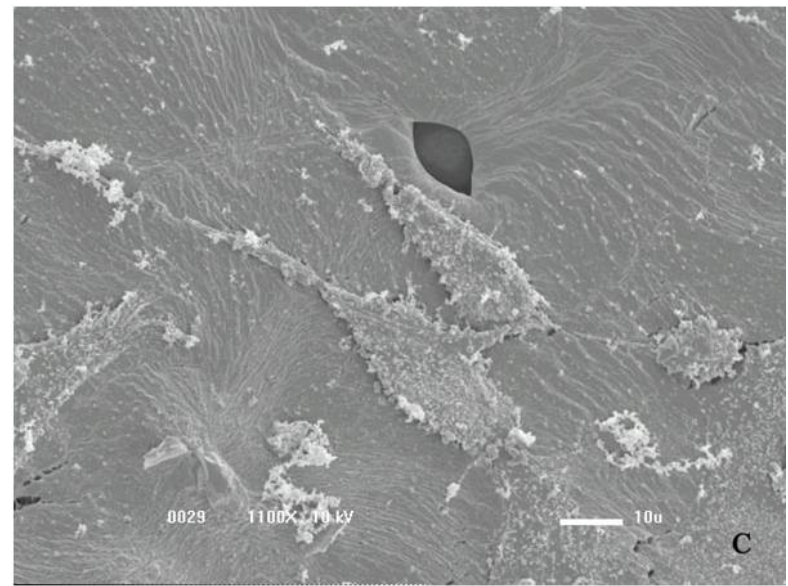

Figura 2: Microscopia eletrônica de varredura (MEV) de células Vero sobre o biomaterial, após 2 horas de cultivo. (A) PLGA 0 sem tratamento; (B) PLGA 1, tratado por plasma de oxigênio pressão 1; (C) PLGA 2, tratado por plasma de oxigênio pressão 2 .

A análise por microscopia eletrônica de varredura, mostrou que ocorre interação entre PLGA/células Vero, com apenas 2 e 48 horas de cultivo. As superfícies das membranas de PLGA 1 apresentaram maior número de células aderidas, com perfil alongado característico de células fibroblásticas. Estas características mostraram-se mais evidentes nas células cultivadas em membranas tratadas com plasma de $\mathrm{O}_{2}$. Foi possível observar a presença de material particulado entre projeções das superfícies celulares, sugerindo um aumento da atividade metabólica das células quando comparadas às outras amostras. Essas características ultraestruturais são consideradas como resultantes da capacidade de células Vero secretarem componentes da matriz extracelular [25].
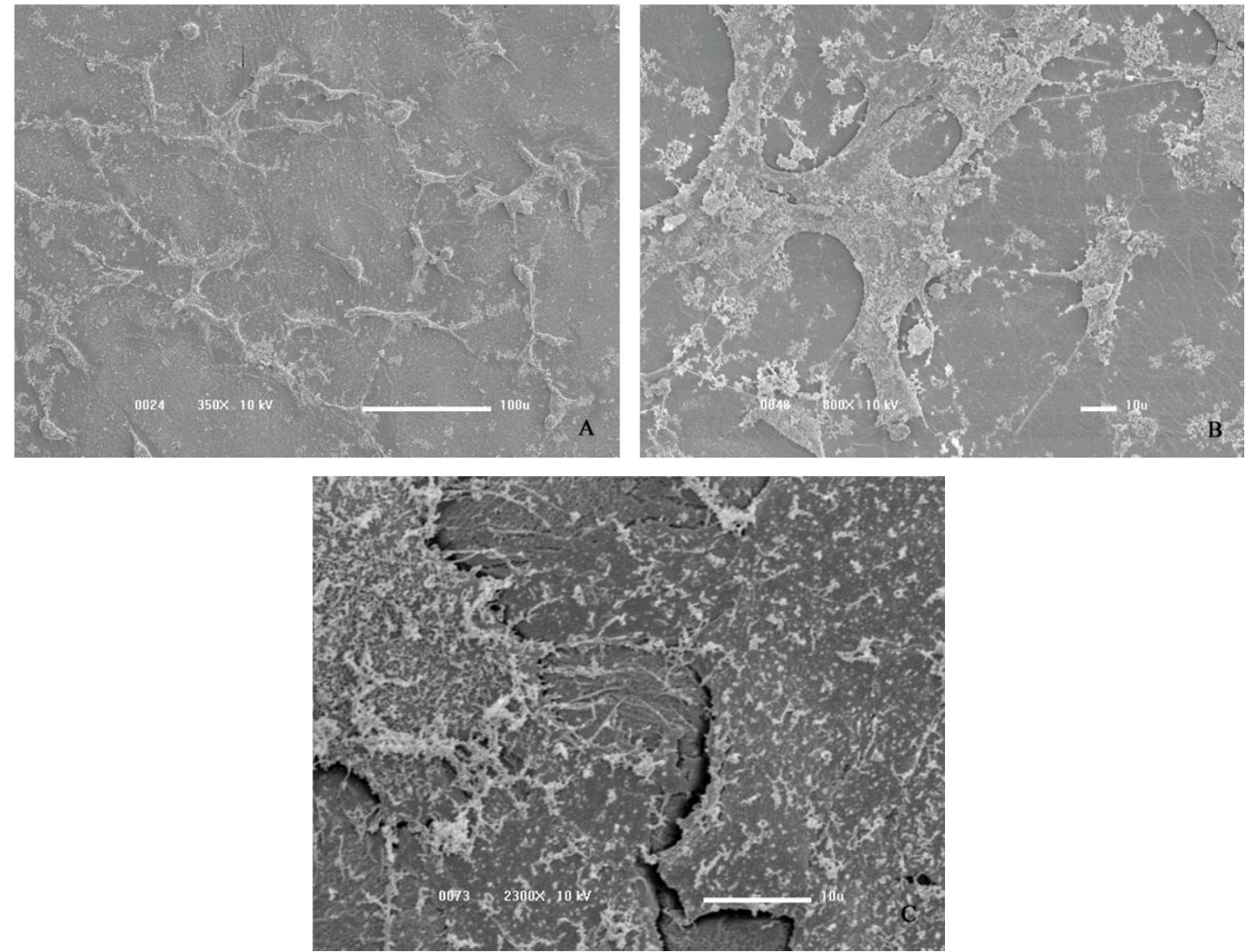

Figura 3: Microscopia eletrônica de varredura (MEV) de células Vero sobre o biomaterial, após 48 horas de cultivo. (A) PLGA 0 sem tratamento; (B) PLGA 1, tratado por plasma de oxigênio pressão 1; (C) PLGA 2 tratado por plasma de oxigênio pressão 2 . 


\subsubsection{Análise Citoquímica}

As células proliferaram sobre o substrato de PLGA e atingiram a confluência. Não foram encontradas alterações citoquímicas, induzidas pelas diferentes superfícies tratadas e não tratadas com plasma de oxigênio. As amostras apresentaram-se gradualmente coradas por AT e XP, em função do tempo de cultivo, mostrando aspecto basófilo e acidófilo, respectivamente (Fig. 4).

Segundo LOMBELLO et al. [4], o citoplasma basófilo sugere que as células são capazes de sintetizar glicosaminoglicanas. Apesar disso, estas produzem moléculas na forma solúvel em meio de cultura, como pode ser verificado nos grupos de proteínas corados com XP (Fig. 4A). Um modelo citoquímico similar foi encontrado em outros biomateriais como poli(HEMA) [4] ou colágeno tipo I. Esses resultados estão de acordo com a descrição de que diferentes tipos celulares são capazes de produzirem matriz sobre polímeros de PLGA [25].
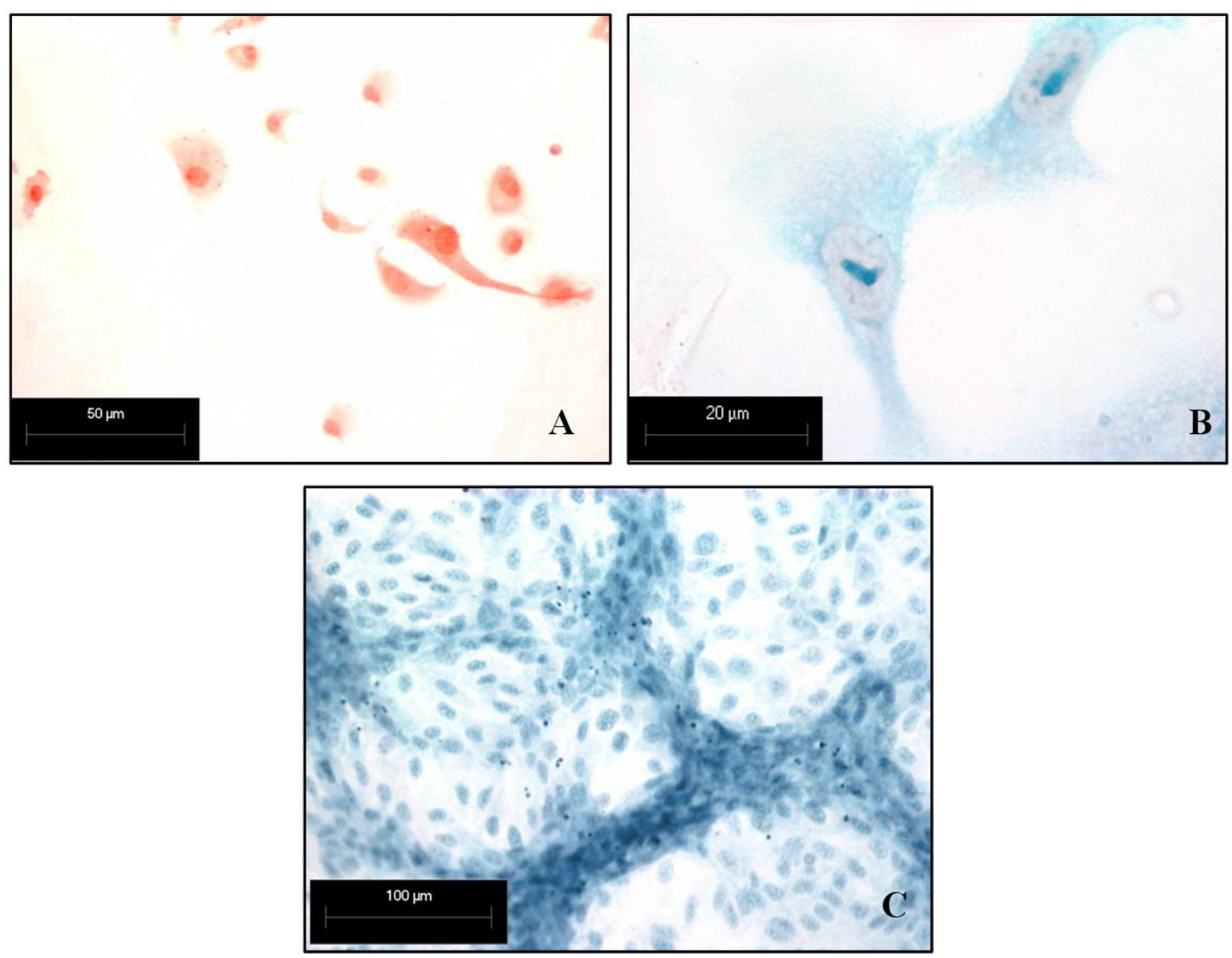

Figura 4: Fotomicrografia de células Vero cultivadas sobre membranas de PLGA. (A) Membrana sem tratamento após 2 horas de cultivo celular. Coloração por Xilidine Ponceau, bar: 50 $\mu \mathrm{m}$; (B) Membrana com tratamento por plasma de oxigênio pressão 1 após 48 horas de cultivo celular. Coloração por Azul de

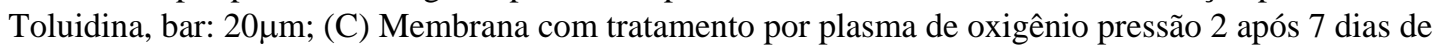
cultivo celular. Coloração por Azul de Toluidina, bar: $100 \mu \mathrm{m}$;

\section{CONCLUSÃO}

As membranas de PLGA tratadas mostraram características desejáveis, onde as células apresentaram uma melhor adesão sobre as superfícies tratadas com plasma e podendo responder alterando seu perfil de diferenciação. $\mathrm{O}$ tratamento por plasma de $\mathrm{O}_{2}$ promoveu um aumento na hidrofilicidade das amostras estudadas, observando-se nas membranas tratadas uma queda nos ângulos de contato e aumento na rugosidade das superfícies das amostras, proporcionando uma boa adesão celular. A partir da MEV, concluise que as membranas de PLGA permitiram a adesão e proliferação celular, independentemente do tratamento realizado. O presente estudo mostrou que modificações da superfície por plasma de $\mathrm{O}_{2}$ influenciaram a adesão celular. Isso indica que se deve dar atenção à estrutura do polímero e também ao tratamento de suas 
superfícies e/ou incorporar elementos bioativos, pois esses fatores são capazes de influenciar o comportamento celular.

\section{BIBLIOGRAFIA}

[1] WAN, Y., QU, X., LU, J., et al., “Characterization of Surface Property of poly(lactide-co-glycolide) after Oxigen Plasma Treatment”, Biomaterials, v. 25, n. 19, pp. 4777-4783, Aug. 2004.

[2] NEMUT, M.V., EASOM, P., HIRST, E.M.A., et al., "Cell/substratum Adhesions in RSV-transfoemed rat Fibroblasts”, Experimental Cell research, v. 193, n. 2, pp. 382-397, Apr. 1991.

[3] KLEBER, R.J., BENTLEY, K.L., SCHOEN, R.C., “Adhesive Substrates for Fibronectin”, Journal Cell Physiology, v. 109, n. 3, pp. 481-488, Dec. 1981.

[4] LOMBELLO, C.B., MALMONGE, S.M., WADA, M.L.F., "Morphology of Fibroblastic Cells Cultured on poly(HEMA-co-AA) Substrates”, Cytobios, v. 101, n. 397, pp. 115-122, Jan. 2000.

[5] REGINATO, A.M., IOZZO, R.V., JIMENEZ, A.S., "Formation of Nodular Structures Resembling Mature Articular Cartilage in long-term Primary Cultures of Human Fetal epiphyseal chondrocytes on a Hydrogel Substrate”, Arthritis and Rheumatism, v. 37, n. 9, pp. 1338-1349, Sep. 1994.

[6] SANTOS JR, A.R., FERREIRA, B.M.P., DUEK, E.A.R., et al., "Differentiation Pattern of Vero cells Cultured on Poly(L-Lactic Acid)/Poly(Hydroxybutyrate-co-hHydroxyvalerate) Blends”, Artificial Organs, v. 28, n. 4, pp. 381-389, Apr. 2004.

[7] FERREIRA, B.M.P., “Obtenção, Caracterização, Estudo in vitro e in vivo de Blendas de PLLA/PHB”, Tese de D.Sc., FEM/UNICAMP, Campinas, SP, Brasil, 2002.

[8] FERREIRA, B.M.P., NASCENTE, P.A.P., FERREIRA, M.J., et al., "Study of the surface modification of biodegradable polymeric membranes by plasma”, Surface and Coatings Technology, (em submissão), 2006.

[9] FAVIA, P., SARDELLA, E., GRISTINA, R., et al., "Plasma Microstructuring of Polymers for Contact Guidance of Cells”, In: International Conference on Advances of Biomaterials for Reconstructive Medicine, pp. 74-75, Capri, Jun. 2002.

[10] CHU, P.K., CHEN, J.Y., WANG, L.P., et al., "Plasma-surface Modification of Biomaterials”, Materials Science and Engineering Review, v. 36, n. 5-6, pp. 143-206, Mar. 2002.

[11] CROLL, T.I., O’CONNOR, A.J., STEVENS, G.W., et al., "Controllable Surface Modification of poly(lactic-co-glycolic acid) (PLGA) by Hydrolysis or Aminolysis I: Physical, Chemical, and Theoretical Aspects”, Biomacromolecules, v. 5, n. 2, pp. 463-473, Mar-Apr. 2004.

[12] KAMINSKA, A., KACZMAREK, H., KOWALONEK, J., "The Influence of Side Groups and Polarity of Polymers on the Kind and Effectiveness of their Surface Modification by air Plasma Action”, European Polymer Journal, v. 38, n. 9, pp. 1915-919, Set. 2002.

[13] YANG, J., BEI, J., WANG, S., "Enhanced Cell Affinity of poly(D,L-Lactide) by Combining Plasma Treatment with Collagen Anchorage”, Biomaterials, v. 23, n. 12, pp. 2607-2614, Jun. 2002.

[14] SANTOS JR, A.R., BARBANTI, S.H., DUEK, E.A.R., et al., "Vero Cell Growth and Diferentiation on poly(L-lactic acid) Membranes of Different Pore Diameters”, Artificial Organs, v. 25, n. 1, pp. 7-13, Jan. 2001.

[15] MA, Z., GAO, C., GONG, Y., et al., "Chondrocyte Behaviors on poly-L-lactic acid (PLLA) Membranes Containing Hydroxyl, Amide or Carboxyl Groups”, Biomaterials, v. 24, n. 21, pp. 3725-3730, Sep. 2003. 
[16] WAN, Y., YANG, J., YANG, J., et al., “Cell Adhesion on Gaseous Plasma Modified poly- (L-lactide) Surface Under Shear Stress Field”, Biomaterials, v. 24, n. 21, pp. 3757-3764, Sep. 2003.

[17] TEZCANER, A., BUGRA, K., HASIRCI, V., "Retinal Pigment Epithelium Cell Culture on Surface Modified poly (hydroxybutyrate - co - hydroxyvalerate) Thin Films”, Biomaterials, v. 24, n. 25, pp. 4573-4583, Nov. 2003.

[18] GENARI, S.C., DOLDER, M.A.H., WADA, M.L.F., “Scannig and Transmission Electron Microscopy of Transformed Vero Cells, with Altered in vitro Growth Characteristics”, Journal Submicroscopy Cytology Pathology, v. 28, n. 4, pp. 565-572, Oct. 1996.

[19] PINHO, F.O., JOAZEIRO, P.P., SANTOS JR., A.R., “Avaliação do Crescimento e Diferenciação de Células Osteoblásticas Humanas sobre Matriz Óssea Desmineralizada (MOD)”, In: Congresso Latino Americano de Biomateriais, pp. 164, Campinas, Jul. 2004.

[20] REZENDE, C.A., DUEK, E.A.R., "Blendas de poli (ácido lático-co-ácido glicólico)/ poli (ácido lático): Degradação in vitro”, Polímeros: Ciência e Tecnologia, v. 13, n. 1, pp. 36-44, Jan. 2003.

[21] KWEON, H.Y., YOO, M.K., PARK, I.K., et al., “A Novel Degradable Polycaprolactone Networks for Tissue Engineering”, Biomaterials, v. 24, n. 5, pp. 801-808, Feb. 2003.

[22] YAMAGUCHI, M., SHINBO, T., KANAMORI, T., et al., "Surface Modification of poly(L-lactic acid) Affects Initial Cell Attachment, Cell Morphology, and Cell Growth”, Artificial Organs, v. 7, n. 4, pp. 187-193, Dec. 2004.

[23] WAN, Y., WANG, Y., LIU, Z., et al., "Adhesion and Proliferation of OCT-1 osteoblast-like Cells on micro- and nono-scale Topography Structured poly (L-lactide)”, Biomaterials, v. 26, n. 21, pp. 4453-4456, Jul. 2005.

[24] BERRY, C., CAMPPBELL, G., SPADICCINO, A., et al., "The Influence of Microscale Topography on Fibroblast Attachment and Motility”, Biomaterials, v. 25, n. 26, pp. 5781-5788, Nov. 2004.

[25] SANTOS JR, A.R., DOLDER, H., WADA, M.L.F., "Dexamethasone and Fetal Calf Serum Effects in Differentiation of Vero Cells Cultures on type I Collagen gel”, Journal Submicroscopy Cytology Pathology, v. 35, n. 1, pp. 35-42, Jan. 2003. 